\title{
Effects of the smoking process on odour characteristics of smoked herring (Clupea harengus) and relationships with phenolic compound content
}

\author{
Mireille Cardinal $^{\mathrm{a}^{*}}$, Josiane Cornet ${ }^{\mathrm{a}}$, Thierry Sérot ${ }^{\mathrm{b}}$ and Régis Baron ${ }^{\mathrm{a}}$ \\ 'Laboratoire de Génie Alimentaire, IFREMER, BP 21105, 44311 Nantes Cedex 3, France \\ baboratoire de Biochimie Alimentaire Industrielle, ENITIAA, BP 82225, 44322 Nantes Cedex 3, France \\ *: Corresponding author : Tel.: +33 2403740 61; fax: +332 403740 71. cardinal@ifremer.fr
}

\begin{abstract}
The relationship between smoking parameters and odour characteristics, evaluated by a trained sensory panel, were studied on smoked herring. In addition, a possible correlation between the content of 10 phenolic compounds and sensory perceptions was investigated. Five smoking techniques were applied, combining smoke production conditions, performed by pyrolysis of beech wood sawdust or by friction of beech wood log, with smoke deposition, either in a controlled kiln (traditional smoking) or by an electrostatic process. In the fifth smoking technique, a purified condensate of beech smokes was vaporised on fish fillets in the smokehouse. The time of smoking was $3 \mathrm{~h}$ for traditional smoking and the liquid smoke atomisation process and 12 min for the electrostatic method. The effects of three smoking temperatures $\left(16,24,32{ }^{\circ} \mathrm{C}\right)$ were tested for both the traditional and the liquid smoke atomisation processes, as well as the effect of the position of the exhaust valve in the smokehouse in the case of the traditional method. Two different voltages were applied for the electrostatic process, 37 and $42 \mathrm{kV}$.

The results show a clear discrimination of the products since some odour characteristics are specifically related to the smoking process applied. All the studied parameters (smoke generation, deposition of smoked compounds, smoking temperature, exhaust valve opening in the smokehouse or voltage applied in the electrostatic tunnel) have an effect on the smell characteristics of smoke products, either on the odour intensity and/or on the kind of smoke note.

Multiple linear models were tested to find relationships between sensory properties and phenolic compounds. Although some compounds seem to be mainly involved in the "cold ash" note, the results illustrate the difficulty of reaching clear conclusions about a correlation between smoke odour and only 10 phenolic compounds. It is suggested that a better model could be found if other volatile compounds, besides the phenolic class, are taken into account.
\end{abstract}

Keywords: Herring; Smoking; Phenolic compounds; Sensory evaluation; Odour characteristics 


\section{Introduction}

The production of smoked and salted fish is an important industry in France and represents $17 \%$ of the market share for aquatic product consumption (Girard \& Paquotte, 2003). The increase in smoked fish consumption began in the 90's with the development of smoked salmon, now the most consumed smoked species before trout and herring. The smoking sector is of considerable economic importance for the seafood market. Each year 45000 tons of salmon are used in France to produce 18000 tons of smoked salmon, $15 \%$ of which is exported to Italy, Belgium and, to a lesser extent, Germany (OFIMER, 2004).

A recent European study on smoked salmon quality (Cardinal, Gunnlaugsdottir, Bjoernevik, Ouisse, Vallet \& Leroi, 2004) showed that the European market offers a large range of products with different salt levels and different phenol contents (the criteria used until now as indicators of smoking treatment intensity) and that sensory characteristics allow products to be classified in different groups. Moreover, the preference study, carried out in the same project with consumers from various European countries, indicated that all consumers do not like the same kind of products. Five classes of consumer with different preferences were identified (Anonymous, 2004). These preferences are related to specific sensory properties. For example, it appears that, for the groups of consumers whose preferences are mainly explained by smoke odour or flavour, not only is the intensity of smoking important but also the kind of smoke note. While some people require a strong smoke odour and flavour, others want a specific "wood fire smoke" note. The control of this smoke characteristic can be of real interest to processors who want to adapt their products to consumer demand. In the past, smoking parameters, such as the kind of generator, kind of wood, hygrometry or temperature of the smokehouse and their effects on the deposit of compounds, have been studied by different research teams (Daun, 1972; Girard, Talon, \& Sirami, 1982; Girard, 1988). The 
number of volatile compounds identified in a smoke, more than 400 , explains the difficulty of relating sensory perception to specific molecules (Maga, 1987; Cardinal, Berdagué, Dinel, Knockaert \& Vallet, 1997). Recent studies performed on phenolic compounds (Guillard \& Grondin, 2003; Sérot, Baron, Knockaert \& Vallet, 2004) have shown that their deposition depends on the smoking conditions and research conducted so far has suggested that phenolic compounds play a key role in smoke perception. However, the relationship between these compounds and sensory perception is not well detailed in the literature, especially for fish products, although some authors cited by Maga (1987), such as Toth \& Potthast (1984), have evaluated the effect of some pure molecules in solution on sensory properties. More recently, the study of Ojeda, Barcenas, Pérez-Elortondo, Albisu \& Guillen (2002) has shown the difficulty to associate molecules to specific terms for the description of smoke flavourings.

This study aims to investigate the effects of smoking processes on the odour of smoked product and to confirm the possible relation between phenolic compound content and sensory perception. It forms part of the same investigation as that carried out by Sérot et al. (2004). This previous work clearly indicated that the process applied affects the content of phenolic compounds, so knowledge about the effect of these compounds on sensory properties would allow the process to be adapted according to the target product.

For practical and cost reasons, herring fillets were used. Two smoke generation techniques were tested, one based on the pyrolysis of sawdust sustained by air circulation (autocombustion) and the second producing smoke by friction of wood log. For each type of smoke generation, two different ways of smoke deposition were compared; exposure of fillets in a closed airconditioned smokehouse (the traditional process) and the electrostatic method where smoke is accelerated towards fillets (Collignan, Knockaert, Raoult-Wack, \& Vallet, 1992; Bardin, Desportes, Knockaert \& Vallet, 1997). The effects of these four techniques were compared to a fifth, the atomisation of liquid smoke. 
2. Material and methods

\subsection{Fish samples}

Frozen fillets of herring (Clupea harengus) were purchased from the local fish market (Nantes, France). On the day of processing, herring was thawed at $+4^{\circ} \mathrm{C}$ for $6 \mathrm{~h}$, hand-salted with refined salt for $20 \mathrm{~min}$ at $12^{\circ} \mathrm{C}$ before being rinsed on grids with water $\left(15^{\circ} \mathrm{C}\right)$ and stored in a cold room at $2{ }^{\circ} \mathrm{C}$ for $14 \mathrm{~h}$ until smoking.

\subsection{Fish processing}

11340 fillets were processed for each treatment. Production of smoke was performed by pyrolysis at $114450^{\circ} \mathrm{C}$ of beech wood sawdust (Thirode, France) or by friction of beech wood $\log$ at $350^{\circ} \mathrm{C}$ 115 (Muvero, The Netherlands). For each kind of smoke production, two different methods of smoke 116 deposition were tested. The first one was direct fillet exposure (traditional smoking) in a 117 smokehouse with a capacity of $380 \mathrm{~kg}$ mounted on a trolley with 28 grids (Thirode, PC 90 118 Model, France) and a relative hygrometry of $65 \% \pm 3 \%$, an air speed of $2 \mathrm{~ms}^{-1}$ above the 119 products and with the exhaust valve position one-third open (1/3) or totally open (3/3). The 120 second way consisted of an electrostatic method where smoke was led through an experimental 121 tunnel $(4000 \times 100 \times 150 \mathrm{~mm})$. This allowed continuous smoking with a production capacity of $122125 \mathrm{~kg} / \mathrm{h}$. The voltage applied between the positive pole (smoke ionisation) and the cathode 123 (conveyor belt) was set by an HT14B high voltage supply (Sefelec, France). The distance 124 between electrodes was $12 \mathrm{~cm}$. Two positive voltages were tested, 37 and $42 \mathrm{kV}$, and the air 125 speed above the fillet was around $0.5 \mathrm{~ms}^{-1}$. The anode electrode, in stainless steel $316 \mathrm{~L}$, was a 126 rectangular grid with 4.5 by $2 \mathrm{~cm}$ spacing of bars $0.2 \mathrm{~cm}$ in diameter. The time of smoking was 3 127 hours for the traditional method at $16^{\circ} \mathrm{C}, 24^{\circ} \mathrm{C}$ or $32^{\circ} \mathrm{C}$, and $12 \mathrm{~min}$ for the electrostatic method 
128 at ambient temperature. The initial product temperature was considered to have a potential

129 impact on smoke compound deposit so two temperatures were tested, 10 and $20^{\circ} \mathrm{C}$.

130 For the liquid smoke atomisation process, a purified condensate of beech smoke associated with

131 aromatic additives (reference 1165) was purchased from Lutetia (France) and vaporised in the 132 smokehouse (Thirode) for 3 hours. All the smoking parameters are presented in Table 1. 133 Twenty-one different treatments were studied.

134 All the herring fillets were vacuum packed, frozen and stored for one month at $-20^{\circ} \mathrm{C}$ until 135 analysis of phenolic compounds and sensory evaluation.

\subsection{Sensory evaluation}

138 A descriptive test with conventional profiling (Stone \& Sidel, 1985) was performed on the odour 139 characteristics of smoked herring with twelve trained panellists belonging to the IFREMER staff. 140 This panel has many years of experience in the sensory evaluation of smoked fish. Before 141 starting the study, a session was organised in order to select sensory descriptors for the product 142 odour and to check the panellists' understanding of the descriptors. Table 2 gives the list of 143 odours and their description. An experimental design was constructed in order to balance the 144 characteristics and odour intensity of the products presented within a session. Five sessions were organised to test all the products, four with a presentation of four products and one with five products.

147 Sessions were performed in individual partitioned booths, as described in procedure NF V-09148105 (AFNOR, 1995) and equipped with a computerised system (Fizz, Biosystèmes, Couternon, 149 France). Panellists rated the sensory attributes on a continuous scale displayed on a computer 150 screen, from low intensity (0) to high intensity (10).

151 On the day of evaluation, 10 herring fillets from each process were thawed, cut into pieces, mixed together to reduce individual variability in fillets and put into closed flasks. Products were 
153

assigned 3-digit numbers, randomised and served simultaneously after $30 \mathrm{~min}$ at ambient temperature.

\subsection{Phenolic compound analysis}

A simultaneous steam distillation solvent extraction (SDE) of smoke compounds was performed in a Likens-Nickerson (1964) apparatus according to Tanchotikul and Hsieh (1989). The SDE extracts were stored at $-20^{\circ} \mathrm{C}$ before gas chromatography analysis. A derivatisation step (silylation) was performed before analysis. Conditions of gas chromatography are detailed in Sérot et al. (2004). 10 phenolic compounds were analysed: phenol, p-cresol, o-cresol, guaiacol, 4-methyl guaiacol, 4-ethyl guaiacol, syringol, eugenol, 4-propyl guaiacol and isoeugenol. These compounds have previously been identified by Sérot and Lafficher (2003) as major phenolic components of smoked fish.

\subsection{Statistical analysis}

Analysis of variance (ANOVA) was performed on sensory data using Statgraphics Plus 5.1 software (Sigma Plus, Paris, France). The significant statistical level was set at $\mathrm{p}<0.05$. Multivariate data processing was performed with Uniwin Plus 5.0 software (Sigma Plus, Paris, France). Principal component analysis (PCA) with standardisation was performed on the means of the sensory scores and the means of each phenolic compound percentage were added as supplementary variables.

\section{Results-Discussion}

\subsection{Sensory characteristics}

An analysis of variance was carried out with the effects of assessors and products on scores of each odour attribute given by the 12 panellists. The main results are presented in Table 3 
according to a modified Flash table (Schlich, 1998) where descriptors are sorted in columns by decreasing $\mathrm{F}$ value and products are sorted in rows by increasing mean for the first attribute of the table. The grand mean and the standard deviation calculated for the 21 products are also included in the table and allow a rapid analysis of attributes as main contributors to discriminate samples. A $(+)$ sign is added when the means score is higher than the grand mean plus one standard deviation, a (-) sign when the means score is lower than the grand mean minus one standard deviation. For easier reading, only the means corresponding to these criteria are given; means close to the general mean are not presented in the table. The descriptors "cold ash", "global intensity" and "fat fish" odours have the highest F values for product effect with a highly significant $p$-value. This means that great differences exist between samples for these odours.

Two extreme groups of products are identified. The first one presents a very high global odour intensity with a specific "cold ash" note. Samples smoked by the traditional process using an autocombustion generator (AT) constitute this group. The second group, with extreme and opposite characteristics, gathers samples processed with a friction generator, associated with an electrostatic method of smoke deposition (FE). They have a low odour, mainly "fat fish" and "brine" odours, even "rancid" for one of them. We can suppose that the low level of smoke notes contributes to the perception of odours more related to fish characteristics. Fish samples that have been smoked at an initial product temperature of $20^{\circ} \mathrm{C}$ present the lowest "wood smoke" characteristics in this group. Samples smoked with an electrostatic process but with an autocombustion generator (AE) have similar characteristics to other samples smoked by an electrostatic method (FE), a rather low odour but a lower "fat fish" score. Other odours, such as "caramel", "butter" and "wood fire smoke" notes are detected when a voltage of $42 \mathrm{kV}$ is used. A principal component analysis (PCA) with standardisation performed on the panel mean scores, obtained for each descriptor of the 21 products, allows the results from Table 3 to be completed and shows a general view of the main characteristics of the samples. Fig. 1 illustrates that the 
203 first principal component is mainly defined by descriptors related to smoke, such as "global 204 intensity", "cold ash", "rubber" and "phenol", and to fish characteristics, such as "fat fish" and 205 "brine". Projection of samples in the first 1-2 plane (Fig. 2) gives the respective location of the 206 products and shows the intermediate characteristics of liquid smoke (L) and friction/traditional207 processed samples (FT) with regard to their global odour intensity. Indeed, samples are ranked 208 along the first component (46.7\%) according to their odour intensity, from strong note on the left 209 -hand side to low odour on the right-hand side of the figure. The second axis (15.7\%) consists 210 mainly of the "vegetable" odour on the positive axis and "caramel" and "wood fire" on the 211 negative axis. The position of $(\mathrm{L})$ products at the top of the figure is due to their "vegetable" note 212 detected in the three samples, whatever the smoking temperature. Regarding samples processed 213 by a friction generator and traditional smoking (FT), they can have specific odours such as 214 "wood fire smoke", "butter" and, to a lesser extent, "caramel", particularly when smoked under $21532^{\circ} \mathrm{C}$. If the smoking is performed at $32^{\circ} \mathrm{C}$ with a one-third open valve, products smell a little of 216 "rubber".

217 These results show that all the studied parameters (smoke generation, deposition method, 218 smoking temperature, exhaust valve opening in the smokehouse or voltage applied in the 219 electrostatic tunnel) have an effect on the smell characteristics of smoked products, either on 220 odour intensity and/or on the kind of smoke note.

\section{Smoke generator effect}

223 The comparison of the level of smoking of the samples, evaluated by the odour intensity, shows 224 that the friction generator has a lower efficiency for smoke production compared to the 225 autocombustion generator. The difference is clearly observed for traditional smoking and, to a 226 lesser extent, for the electrostatic smoking method. The difference in smoke production 227 temperature, $350^{\circ} \mathrm{C}$ for friction and around $450^{\circ} \mathrm{C}$ for pyrolysis of sawdust, leads to a less 
228 advanced degradation of wood with friction compared to the autocombustion method 229 (Knockaert, 1990) and the oxidation of the volatile compounds occurs to a lesser extent. This 230 could be the reason for the differences in the sensory features observed.

\section{Temperature effect}

233 For smoke production by sawdust pyrolysis, sensory perception is slightly affected by an 234 increase in temperature when the exhaust valve is completely open since samples smoked at $23516^{\circ} \mathrm{C}$ have lower scores for odour global intensity and "ash" note than those of samples smoked 236 at $24^{\circ} \mathrm{C}$ or $32^{\circ} \mathrm{C}$. When the valve is one-third open, odours of samples become "phenolic" and 237 "rubber", mainly for smoking temperatures of $16^{\circ} \mathrm{C}$ and $24^{\circ} \mathrm{C}$, while the samples smoked at $23832^{\circ} \mathrm{C}$ have the strongest global odour.

239 The results show that our smoking conditions lead to products with high smoke notes for all the 240 temperatures tested but a high temperature, like $32^{\circ} \mathrm{C}$, during the smoking step allows potential 241 compounds with a higher molecular weight involved in the smoking effect to remain in the 242 vapour phase (Potthast 1977, 1978; Girard, 1988) and therefore to be deposited in higher 243 proportions.

244 Conclusions about the temperature effect with a friction smoke generator are quite similar, even 245 though the smoke perception is less intense than with autocombustion. There is an increase in 246 global smell intensity with temperature, with the two valve positions tested (Fig. 2). The lower 247 level of smoking allows the modification of sensory characteristics related to temperature to be 248 followed with more accuracy without a saturation effect.

249 Smell characteristics of samples smoked by vaporisation of liquid smoke are also affected by temperature. The mean score of "cold ash", given by the trained panel, increases with temperature as well as the "earthy" note. At the same time, "vegetable" odour, a specific characteristic of this kind of product, and "brine" odour decrease. Differences are mainly 
observed between the $16^{\circ} \mathrm{C}$ smoked samples and those smoked at $32^{\circ} \mathrm{C}$. As shown by Sérot et al. (2004), a temperature of $16^{\circ} \mathrm{C}$ does not allow the deposition of a great quantity of phenolic compounds, probably because of the low vaporisation of the liquid smoke, and this phenomenon could explain the sensory differences.

\section{Exhaust valve position effect}

The effect of the exhaust valve position is mainly observed for the autocombustion process. If the exhaust valve is one-third open, meaning a longer residence time for the smoke in the kiln, all the products have the same strong global intensity with a "cold ash" specificity. It is likely that, in these conditions, the level of smoke compound deposition is high enough at all the temperatures to reach a saturation point in odour evaluation. When the valve is completely open, the temperature effect is more noticeable. In the case of the friction generator, the position of the valve does not seem to affect odour characteristics.

\section{Smoking method effect}

As previously described, samples smoked using our current electrostatic method have low smoke odours. However, smell characteristics could be modulated when smoke is produced by sawdust pyrolysis (AE). Indeed, in these conditions, a voltage of $42 \mathrm{kV}$ instead of $37 \mathrm{kV}$ gives products with more complex characteristics, lightly "butter", "caramel" and "wood fire". No voltage effect was observed when the electrostatic method and a friction generator (FE) were used. Smoke compounds produced during friction are probably different and therefore it is possible that they do not react equally in the electric field.

\subsection{Relationships between odour characteristics and phenolic compound deposition}


In order to find possible explanations for the sensory characteristics described in relation to the

27810 major phenolic compounds analysed, a projection of the contents of these compounds was made on the first plane of PCA, performed on sensory descriptors. These chemical data were added as supplementary variables. The first plane shows a correlation between the first component and all the phenolic compounds, except eugenol (figure not presented). The content of these molecules increases with the characteristics of "global intensity", "cold ash", "rubber" 283 and "phenolic", which confirms the likely contribution of the phenol classes to smoke aroma as mentioned by many researchers (Lustre \& Issenberg, 1970; Maga, 1987; Girard 1988), The odour intensity of the smoked samples, scored by the trained panel, seems at first to accord with the content of phenolic compounds. However, the study of the relationship between the global odour and the sum of the 10 phenolic compounds (Fig. 3) shows that, if a general trend is 288 observed, the model of prediction of global intensity by total phenolic compounds, though significant, is rather weak $\left(\mathrm{R}^{2}\right.$ adjusted $\left.=30.8 \%\right)$. The same weaker relationship is obtained between the "cold ash" note and the sum of phenolic compounds. The $\mathrm{R}^{2}$ adjusted of this model is $31 \%$. The lack of fit is due partly to the characteristics of the samples smoked by a traditional smokehouse and pyrolysis of sawdust and especially the references AT-16 and AT-24. These products were among the highest sensory score samples for odour intensity but rank in the middle of the range of phenolic contents observed. In contrast, when the smoking temperature was set at $32^{\circ} \mathrm{C}$, samples prepared with liquid smoke (L) or a traditional process with a friction generator (FT) had high contents of total phenolic compounds but intermediate sensory scores. 297 Thus, it could be suggested that not only the total content but also the type of phenolic 298 compounds deposited on the flesh is important. Perception thresholds are different from one 299 compound to another (Leffingwell \& Leffingwell, 1991) and it is therefore obvious that odour characteristics cannot be related only to the quantity of phenolic molecules. 
301 Backward stepwise multiple linear regression was performed between odour characteristics and 302 the analysed phenolic compounds. The results show statistically significant relationships 303 between the "cold ash" note and some phenolic compounds such as o-cresol, p-cresol and, to a 304 lesser extent, 4-ethyl guaiacol and 4-propyl guaiacol. The $\mathrm{R}^{2}$ adjusted of the model is $67.3 \%$, 305 which means that a fair part of the odour variability is not explained by this model. Nevertheless, 306 it does allow identification of molecules that could have the most important impact on "cold ash" 307 odour. In the case of "wood smoke" odour, it was impossible to find a relationship with specific 308 compounds. It is likely that the sensory differences observed were not high enough to identify 309 relationships with phenolic compounds.

310 Sérot et al. (2004) have shown that the content of phenolic compounds increases with the time of 311 processing and the temperature applied but that the relative percentage of these compounds is 312 constant for a given smoking procedure and is independent of the process parameters used. In 313 order to test the hypothesis of a specific effect of the relative composition of phenolic 314 compounds on sensory properties, percentages of phenolic compounds were added as 315 supplementary variables to the PCA carried out with sensory descriptors (Fig. 4). This figure 316 shows correlations between odours scored by the sensory panel and the percentage of each 317 phenolic compound. On the first component, mainly defined by descriptors such as "global 318 intensity", "cold ash", "rubber" and "phenolic" odours, the best correlation with these criteria is 319 observed with the compounds o-cresol, phenol and 4-ethyl guaiacol. In contrast, the sensory 320 descriptors "fat fish", "brine" and "butter", and chemical compounds syringol, isoeugenol and 321 eugenol are positively correlated with the first principal component. As for guaiacol, the work of 322 Sérot et al. (2004) showed that this compound, as well as 4-methyl guaiacol, was identified as 323 the main phenolic compound whatever the process and contributed to the discrimination of 324 processes. However, this molecule does not seem related to a specific odour (Fig. 4) and does not 325 allow the samples map to be explained (Fig. 2). 
Now, with the knowledge of the phenolic compound distribution and the correlation with sensory descriptors, is it possible to propose a hypothesis about the sensory differences observed between samples in Fig. 2 and not predicted by the total phenolic compounds? The case of sample L32 for example is interesting. This product received a lower score for "global intensity" and "cold ash" odour compared to AT products and a high score for "phenolic" odour. We can 331 suppose that its higher phenol percentage (Fig. 2 and Fig. 4) is one of the possible explanations. 332 Indeed, phenol is a compound with a high perception threshold, which could therefore have a 333 lower contribution to smoke odour. Moreover, samples smoked with condensate vaporisation (L) 334 have been described by the specific characteristics "earthy" and "vegetable", which suggests that 335 other volatile compounds are involved in the perception, not only phenolic compounds. These 336 molecules may contribute by adding more aromatic and complex odours but have less effect on 337 smoke odour.

338 In the case of FT samples, and especially FT 32-3, a rather low global intensity is found in spite 339 of its quantity of phenolic compounds. Guaiacol, 4-methyl guaiacol and propyl guaiacol do not 340 discriminate this sample from AT samples but these latter products have higher percentages of 341 phenol and o-cresol. However, if the hypothesis of a small effect of phenol in smoke odour is 342 suggested for samples smoked with vaporisation of condensates, it is difficult to find a contrary 343 effect with AT samples. On the other hand, o-cresol has previously been identified as a 344 compound with a significant effect on the relation between "cold ash" odour and phenolic 345 compounds. This molecule could play an important role in explaining the observed differences. 346 Regarding FT samples, the low global intensity observed in spite of a high percentage of eugenol 347 could also be explained by interaction of this compound with proteins. Indeed, a recent study 348 (Reiners, Nicklaus \& Guichard, 2000) has shown that the addition of protein decreases the odour 349 perception of eugenol. 
350 The results of this experiment and the difficulty of reaching clear conclusions suggest that the

351 study of only 10 phenolic compounds is certainly too restrictive an analysis to understand all the 352 sensory characteristics. Moreover, the simultaneous quantitative and qualitative variation of 353 phenolic compounds leads to a more complex evaluation of their effects.

354 It is certain that molecules other than phenolic compounds are deposited during the traditional 355 process with autocombustion (AT), and that these are also involved in the strong odour detected. 356 Previous work on smoked salmon (Cardinal et al., 1997) has already shown the high global 357 intensity of products processed with this technique and different classes of compound have been specifically identified. Among the molecules found, butenal, 3-methyl butanal, methyl alcanes and aromatic compounds such as m-xylene, styrene and alkyl benzene could be involved in sensory characteristics.

361 Regarding samples smoked in our current conditions using the electrostatic method, the very low 362 level of phenolic compounds deposited is probably the main reason for the low perception of 363 smoked odour. Ruiter (1979) and Sirami (1981) indicated that the electrostatic field modifies the 364 smoke compound ratio in the vapour phase, mainly by increasing the level of carbonyl 365 compounds to the detriment of phenolic compounds. Figures 4 and 2 show that syringol, 366 isoeugenol and eugenol have the strongest correlation with "fat fish", "brine", and "butter" and 367 constitute the main fraction of phenolic compounds in electrostatic samples. Thus, we can 368 suppose that these compounds do not have a great impact on sample odour, for the quantity 369 deposited. The comparison of the phenolic compound profile of the two AE samples treated with 370 two different voltages does not lead to a possible explanation of the characteristics, lightly 371 "butter", "caramel" and "wood fire", detected in the AE sample when a voltage of $42 \mathrm{kV}$ is 372 applied. This shows the difficulty of finding relations between sensory perception and chemical 373 compounds, especially when only one class of compounds has been followed. 
374 However, the results of our study, through the comparison of extreme products, electrostatic 375 samples and autocombustion/traditional samples, tend to confirm the importance of phenolic 376 compounds in smoke perception. They show that some of the 10 compounds analysed determine, 377 to a certain extent, the smoked characteristics of products, even if other molecules can also 378 modulate their perception.

\section{Conclusion}

381 This study has confirmed, through the large range of smoked products investigated, the strong 382 effect of smoking conditions on final odour characteristics. These results also indicate to 383 processors the possibility of adapting smoked characteristics to consumer demand.

384 Products smoked with our current electrostatic process, regardless of the kind of generator, have 385 low smoked characteristics and mainly "fat fish" and "brine" notes but recent results show that some modifications of the equipment could improve smoke deposition. The kind of smoke generator used leads to products not only with different global odour intensities but also different smoke characteristics. The efficiency of the generator with sawdust pyrolysis is observed, especially for the traditional process of smoke deposition since the temperature is high. A general trend is observed about the effect of smoking temperature. The global odour intensity generally increases with the temperature applied in the smokehouse. This is true for both the friction generator and the autocombustion generator. In the latter case, the interactions effect between temperature and other parameters, such as the exhaust valve position, can modulate these results. In particular, when the valve position is one-third open, the sensory characteristics 395 of the samples smoked at 16,24 or $32^{\circ} \mathrm{C}$ are very close. The higher residence time of the smoke could indicate that a saturation point is reached. If the valve is more open, the temperature effect on sensory characteristics is more significant. A temperature of $16^{\circ} \mathrm{C}$ is enough to reach smoked product characteristics without a strong "cold ash" note. This smoking procedure, with an 
autocombustion generator and traditional smoke deposition by direct exposure of fillets, is the 400 most frequent practice in industry. It is therefore of considerable interest for processors to know 401 the effects of these parameters and how to control them.

402 Regarding the role of phenolic compounds on sensory properties, it is not clear enough to give 403 detailed conclusions. If we consider the results of odour characteristics from both electrostatic 404 and traditional smoked products, the content of phenolic compounds seems well related to 405 smoked odour. Although the content of phenolic compounds can be an indicator of smoking 406 intensity, this analysis does not always reflect the odour intensity perceived by a group of 407 panellists. Indeed, phenolic compounds have different perception thresholds and do not have the 408 same impact on sensory perception. Our study suggests that o-cresol, p-cresol and, to a lesser 409 extent, 4-ethyl guaiacol and 4-propyl guaiacol are the main components involved in "cold ash" 410 odour. The study of the relation between sensory descriptors and percentage of each phenolic 411 compound leads to the hypothesis that syringol, isoeugenol and eugenol have no detectable 412 effect on smoke odours, in the tested conditions.

413 However, these results show that it does not seem reasonable to explain the sensory properties of 414 smoked products with only the class of the 10 major phenolic compounds detected in the flesh. 415 Indeed, many other volatile compounds have been identified such as ketones, aldehydes, acids, 416 alcohols, esters, furans, lactones and many other molecules (Maga, 1987). It is suggested that, in 417 order to identify the main compounds involved in the sensory properties of smoked fish, the 418 study be extended to all volatile compounds, taking into account the relative percentage of each 419 component as well as its content in the flesh. Knowledge of the matrix effect on the threshold 420 perception of each compound would be helpful to understand their role in odour characteristics 421 and identify the potent odorants in smoked fish. 
References

425 AFNOR (1995). Directives générales pour l'implantation de locaux destinés à l'analyse sensorielle, V-09-105. In Contrôle de la qualité des produits alimentaires - Analyse sensorielle,

Paris.

Anonymous (2004). European consumer preferences for smoked salmon. Collective report from

European project - QLK1-2000-01575, specific RTD programme "Quality of Life and

Management of Living Resources"- EUROSALMON - Nantes: Adriant.

Bardin, J. C., Desportes, G., Knockaert, C. \& Vallet, J. L. (1997). Improvement in devices for electrostatic smoking of meat products. French Patent $N^{\circ} .9708177$, filing date: June 25.

Birkeland, S., Rora, A. M. B., Skara, T. \& Bjerkeng, B. (2004). Effects of cold smoking procedures and raw material characteristics on product yield and quality parameters of cold smoked Atlantic salmon (Salmo salar L.) fillets. Food Research International, 37, 273-286.

Cardinal, M., Berdagué, J.L., Dinel, V., Knockaert, C. \& Vallet, J.L. (1997). Effet de différentes techniques de fumage sur la nature des composés volatils et les caractéristiques sensorielles de la chair de saumon. Sciences des Aliments, 17, 679-696.

Cardinal, M., Knockaert, C., Torrissen, O., Sigurgisladottir, S., Morkore, T., Thomassen, M. S. \& Vallet, J.L. (2001). Relation of smoking parameters to the yield, colour and sensory quality of 441 smoked Atlantic salmon (Salmo salar). Food Research International, 34, 537-550.

442 Collignan, A., Knockaert, C., Raoult-Wack, A.L. \& Vallet, J.L. (1992). Procédés et dispositif de 443 salage-séchage et de fumage à froid de produits alimentaires carnés. French patent $\mathrm{N}^{\circ} .9208958$, 444 European extension 93430009.6.

445 Daun, H. (1972). Sensory properties of phenolic compounds isolated from curing smoke as 446 influenced by its generation parameters. Lebensm. Wiss. u. Technol., 5(3), 102-105. 
447 Girard, J.P., Talon, R., \& Sirami, J. (1982). Le fumage électrostatique: son efficacité 448 relativement à deux paramètres. Sciences des Aliments, 2, 1-15.

449 Girard J.P. (1988). La fumaison. Technologie de la viande et des produits carnés, ch.7, 171-214, 450 Lavoisier, Paris.

451 Girard, S. \& Paquotte, P. (2003). La consommation des produits de la pêche et de l'aquaculture 452 en France. Cahiers de Nutrition et de Diététique, 38(1), 17-27.

453 Guillard, A.S. \& Grondin, C. (2003). Etude des composés phénoliques de l'arôme des saucisses 454 fumées par micro-extraction en phase solide (SPME). Bulletin de liaison du CTSCCV, 13, 13-17.

455 Knockaert, C. (1990). Le fumage du poisson. Service de la documentation et des publications, 456 IFREMER, Brest.

Leffingwell, J.C. \& Leffingwell, D. (1991) GRAS flavor chemicals detection thresholds. 458 Perfumer and Flavorist, 16, 1-9.

459 Lustre, A.O. \& Issenberg, J. (1970). Phenolic components of smoked meat products. Journal of 460 Agricultural and Food Chemistry, 18, 6, 1056-1060.

461 Maga, J.A. (1987). The flavor chemistry. Food Review International, 3(1, 2), 139-183.

462 OFIMER. (2004). Le marché du saumon, Paris.

463 Ojeda, M., Barcenas, P., Pérez-Elortondo, F.J., Albisu, M. \& Guillen, M.D. (2002). Chemical 464 references in sensory analysis of smoke flavourings. Food Chemistry, 78, 433-442.

465 Potthast, K. (1977). Determination of phenols in smoked meat products. Acta Alimentaria 466 Polonic, 3(3), 189-193.

467 Potthast, K. (1978). Smoking methods and their effects on the content of 3,4-benzo(a)pyrene and 468 other constituents of smoke in smoked meat products. Die Fleischwirtschaft, 58(3), 371-375. 
469 Reiners, J., Nicklaus, S. \& Guichard, E. (2000). Interactions between beta-lactoglobulin and 470 flavour compounds of different chemical classes. Impact of the protein on the odour perception 471 of vanillin and eugenol. Lait, 80, (3), 347-360.

472 Ruiter A. (1979). Color of smoked foods. Food Technology, 33, 54-63.

473 Schlich, P. (1998). What are the sensory differences among coffees? Multi-panel analysis of 474 variance and FLASH analysis. Food Quality and Preference, 9(3), 103-106.

475 Sérot, T. \& Lafficher, C. (2003). Optimisation of solid phase micro-extraction coupled to gas 476 chromatography for the determination of phenolic compounds in smoked herring. Food 477 Chemistry, 82(4), 513-519.

478 Sérot, T., Baron, R., Knockaert, C., \& Vallet, J.L. (2004). Effect of smoking processes on the 479 contents of 10 major phenolic compounds in smoked fillets of herring (Clupea harengus). Food 480 Chemistry, 85, 111-120.

481 Stone, H., \& Sidel, J.L. (1985). Sensory evaluation practices. Academic Press Inc., New York.

482 Tanchotikul, U. \& Hsieh, T.C.Y. (1989). Volatile flavor components in crayfish waste. Journal 483 of Food Science, 54(6), 1515-1520.

484 Toth, L. \& Potthast, K. (1984) Chemical aspects of the smoking of meat and meat products. 485 Advances in Food Research, 29, 87-158. 


\section{Figure captions}

Table 1. Process and experimental conditions of smoking

Table 2. Odour characteristics and description

Table 3. Main odour characteristics of 21 smoked herring samples (mean scores and results of analysis of variance)

$495{ }^{\mathrm{a}} \mathrm{F}$ value of Fisher test

$496{ }^{\mathrm{b}}$ Probability of Fisher test for product effect, significant differences between samples $* \mathrm{p}<0.05$, $497 * * \mathrm{p}<0.01, * * * \mathrm{p}<0.001$,

$498{ }^{\mathrm{c}}$ Grand mean of the 21 products

$499{ }^{\mathrm{d}}$ Standard deviation of the 21 mean scores

$500{ }^{\mathrm{e}}$ Initial product temperature $\left({ }^{\circ} \mathrm{C}\right)$ for the electrostatic method, $10^{\circ} \mathrm{C}$ for all the other products

$501 \quad{ }^{\mathrm{f}}$ Exhaust valve position, $1=1 / 3$ open, $3=3 / 3$ open

504 Figure 1. Projection of variables in the plane 1-2 of the principal component analysis on sensory 505 descriptors for odour

507 Odour: global intensity (iglo), wood fire smoke (wood), cold ash (ash), phenol/medicinal (phen), 508 rubber (rubb), caramel (cara), fat fish (fat), butter (butt), rancid (ranc), brine (brin), dried fish 509 (drie), vegetable (vege), earthy (eart) 
512 Figure 2. Projection of samples in the plane 1-2 of the principal component analysis on sensory

513 descriptors

515 AT: Autocombustion generator and traditional smoking, FT: Friction generator and traditional

516 smoking, AE: Autocombustion generator and electrostatic smoking, FE: Friction generator and

517 electrostatic smoking

$518 \quad 16,24,32$ : smoking temperature $\left({ }^{\circ} \mathrm{C}\right)$

5191 or 3: exhaust valve position

52010 or 20 : initial temperature of fish $\left({ }^{\circ} \mathrm{C}\right)$

522 Figure 3. Relationship between global odour and the total phenolic compounds

$523 \quad \mathrm{R}^{2}$ adjusted $=30.8 \%$

525 Figure 4. Correlation between phenolic compound percentage and components 1 and 2 of the

526 principal component analysis from sensory descriptors

528 Odour: global intensity (iglo), wood fire smoke (wood), cold ash (ash), phenol/medicinal (phen), 529 rubber (rubb), caramel (cara), fat fish (fat), butter (butt), rancid (ranc), brine (brin), dried fish 530 (drie), vegetable (vege), earthy (eart)

$531 \quad$ Phenolic compounds are identified with

532 phenol (phenol), p-cresol (pcresol), o-cresol (ocresol), guaiacol (guaiacol), 4-methyl guaiacol 533 (meguaiacol), 4-ethyl guaiacol (etguaiacol), syringol (syringol), eugenol (eugenol), 4-propyl 534 guaiacol (proguaiacol) and isoeugenol (isoeugenol) 


\begin{tabular}{|c|c|c|}
\hline $\begin{array}{l}\text { Smoke deposit method } \\
\text { Smoke Generation }\end{array}$ & $\begin{array}{c}\text { Traditional method }(\mathbf{T}) \\
\text { direct exposure } \\
\text { smoking time }=3 \mathrm{~h} \\
\end{array}$ & $\begin{array}{c}\text { Electrostatic method }(\mathbf{E}) \\
\text { voltage }(\mathrm{kV}) \quad 37 \text { or } 42 \\
\text { smoking time }=12 \mathrm{~min} \\
\end{array}$ \\
\hline Autocombustion (A) & (AT) & (AE) \\
\hline $\begin{array}{l}\text { Smokehouse temperature }\left({ }^{\circ} \mathrm{C}\right) \\
\text { Initial product temperature }\left({ }^{\circ} \mathrm{C}\right) \\
\text { Exhaust valve opening }\end{array}$ & $\begin{array}{c}16-24-32 \\
10 \\
1 / 3-3 / 3\end{array}$ & $\begin{array}{c}\text { ambient } \\
10 \\
-\end{array}$ \\
\hline Friction (F) & (FT) & (FE) \\
\hline $\begin{array}{l}\text { Smokehouse temperature }\left({ }^{\circ} \mathrm{C}\right) \\
\text { Initial product temperature }\left({ }^{\circ} \mathrm{C}\right) \\
\text { Exhaust valve opening }\end{array}$ & $\begin{array}{c}16-24-32 \\
10 \\
1 / 3-3 / 3\end{array}$ & $\begin{array}{c}\text { ambient } \\
10-20 \\
-\end{array}$ \\
\hline Liquid smoke atomisation (L) & (L) & \\
\hline $\begin{array}{l}\text { Smokehouse temperature }\left({ }^{\circ} \mathrm{C}\right) \\
\text { Initial product temperature }\left({ }^{\circ} \mathrm{C}\right) \\
\text { Exhaust valve opening }\end{array}$ & $\begin{array}{c}16-24-32 \\
10 \\
\text { closed }\end{array}$ & - \\
\hline
\end{tabular}


Table 2.

541

\begin{tabular}{ccc}
\hline Descriptors of odour & label & Description \\
\hline Global intensity & iglo & Overall odour whatever the note \\
Wood fire smoke & wood & Odour of a wood fire \\
Cold ash & ash & Odour of ashes once the fire is out \\
Phenol / Medicinal & phen & Odour of a solution of phenol \\
Rubber & rubb & Odour of a burnt tyre \\
Caramel & cara & Odour of burnt sugar \\
Fat fish & fat & Odour of oil associated with fat fish \\
Butter & butt & Odour developed by butter \\
Rancid & ranc & Odour of oxidised fish oil \\
Brine fish & brin & Odour of fish salted in brine \\
Dried fish & drie & Odour developed by fish meal \\
Vegetable & vege & Odour of freshly cut grass, plant \\
Earthy & eart & Odour of earth or mud \\
\hline
\end{tabular}


Table 3.

\begin{tabular}{|c|c|c|c|c|c|c|c|c|c|c|c|c|c|}
\hline Odours & ash & iglo & fat & eart & ranc & vege & phen & rubb & brin & cara & drie & butt & wood \\
\hline $\mathrm{F}^{\mathrm{a}}$ & 12.0 & 7.9 & 7.0 & 2.7 & 2.6 & 2.4 & 2.4 & 2.2 & 2.2 & 2.0 & 2.0 & 1.8 & 1.7 \\
\hline$P^{b}$ & *** & $* * *$ & $* * *$ & *** & *** & *** & *** & ** & ** & ** & * & * & * \\
\hline Gmean $^{\mathrm{C}}$ & 2.6 & 6.4 & 2.9 & 1.1 & 1.3 & 1.1 & 0.9 & 0.8 & 1.7 & 0.5 & 1.3 & 0.9 & 2.8 \\
\hline$s t d^{d}$ & 2.0 & 1.0 & 1.3 & 0.8 & 0.7 & 0.8 & 0.6 & 0.5 & 0.7 & 0.4 & 0.6 & 0.6 & 0.8 \\
\hline $\mathrm{FE}+42$ & $0.2-$ & 5.3- & $4.9+$ & 0.3 & & & $0.2-$ & $0.1-$ & $2.7+$ & $0.1-$ & $0.2-$ & & \\
\hline $\mathrm{FE}+37-20^{\mathrm{e}}$ & $0.3-$ & & $4.8+$ & & $3.0+$ & & & & $2.5^{+}$ & $0.1-$ & $0.5-$ & & $1.9-$ \\
\hline$F E+42-20$ & $0.5-$ & $5.1-$ & $4.4+$ & $0.2-$ & & & & & $2.5^{+}$ & & & & $2.0-$ \\
\hline FT16-3 ${ }^{f}$ & & & & $0.3-$ & & & $0.3-$ & & & $0.1-$ & & $1.7+$ & \\
\hline FT16-1 & & & & & & & $0.3-$ & $0.3-$ & $2.6+$ & & $0.4-$ & $2.0+$ & $3.7+$ \\
\hline $\mathrm{FE}+37$ & & $5.1-$ & $4.8+$ & & & & & & & & & & \\
\hline FT24-3 & & & $4.7+$ & $0.3-$ & $3.0+$ & & & & & $0.9+$ & $2.2+$ & & \\
\hline$A E+37$ & & $5.2-$ & & & & & $0.2-$ & & & & $0.6-$ & & \\
\hline L16 & & & & & & $3.5+$ & $2.0+$ & & & & & & 1.8- \\
\hline$A E+42$ & & & & & & & & & $2.8+$ & $1.4+$ & $0.6-$ & $1.6+$ & $4.0+$ \\
\hline FT32-3 & & & & $0.2-$ & & & $0.3-$ & & $1.0-$ & & & & \\
\hline FT24-1 & & & & & & & & & $2.8+$ & $1.6+$ & & $1.9+$ & $4.1+$ \\
\hline FT32-1 & & & & & $2.0+$ & $0.3-$ & & $1.4+$ & & & $2.3+$ & & \\
\hline L24 & & & & $2.5+$ & & $2.4+$ & & & & $0.9+$ & & & \\
\hline AT16-3 & & & & & & & & & & $0.9+$ & & $0.3-$ & \\
\hline L32 & & & & $2.6+$ & & $2.0+$ & $1.7+$ & & $1.0-$ & & & $0.3-$ & $1.4-$ \\
\hline AT32-3 & $4.6+$ & $7.6+$ & $1.1-$ & $2.2+$ & $0.6-$ & 0.4 & & & $0.9-$ & $0.1-$ & $2.4+$ & $0.1-$ & \\
\hline AT24-1 & $5.3+$ & $7.5+$ & & & & $0.3-$ & $1.8+$ & $1.7+$ & & & & $0.1-$ & \\
\hline AT16-1 & $5.7+$ & $7.7+$ & $1.5-$ & & & & $2.1+$ & $2.3+$ & & $0.9+$ & & & \\
\hline AT32-1 & $6.1+$ & $8.4+$ & $1.3-$ & & $0.3-$ & & & $1.3+$ & $0.6-$ & & & $0.3-$ & $4.4+$ \\
\hline AT24-3 & $6.4+$ & $7.6+$ & & & & & & & $0.6-$ & & & $0.3-$ & 1.7- \\
\hline
\end{tabular}

${ }^{\mathrm{a}} \mathrm{F}$ value of Fisher test

${ }^{\mathrm{b}}$ Probability of Fisher test for product effect, significant differences between samples $* \mathrm{p}<0.05$, $550 * * \mathrm{p}<0.01, * * * \mathrm{p}<0.001$,

$551{ }^{\mathrm{c}}$ Grand mean of the 21 products

$552{ }^{\mathrm{d}}$ Standard deviation of the 21 mean scores

$553{ }^{\mathrm{e}}$ Initial product temperature $\left({ }^{\circ} \mathrm{C}\right)$ for the electrostatic method, $10^{\circ} \mathrm{C}$ for all the other products $554{ }^{\mathrm{f}}$ Exhaust valve position, $1=1 / 3$ open, $3=3 / 3$ open 
556 Figure 1.

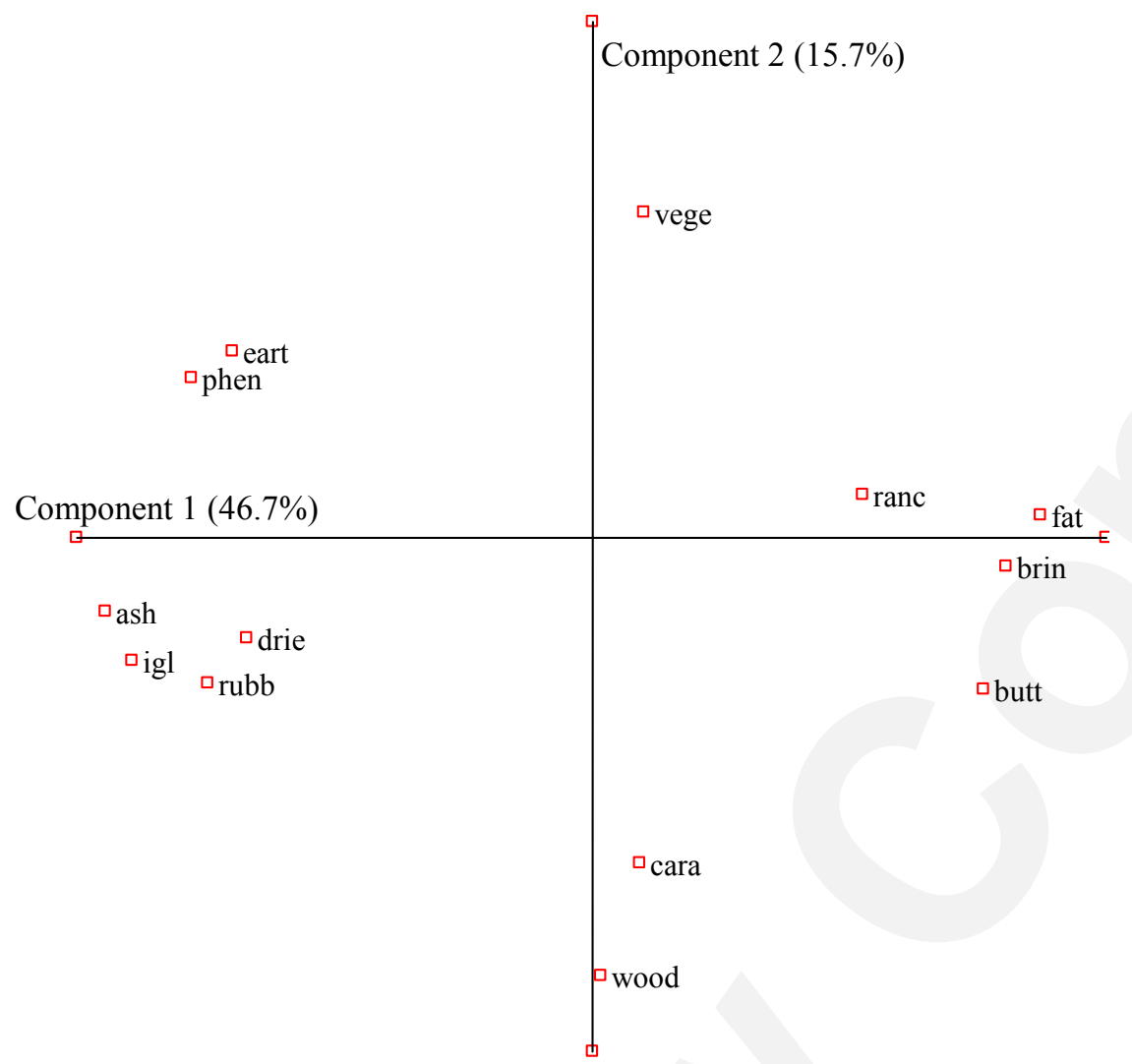

557

558

559

560 
560

561

562

Figure 2.

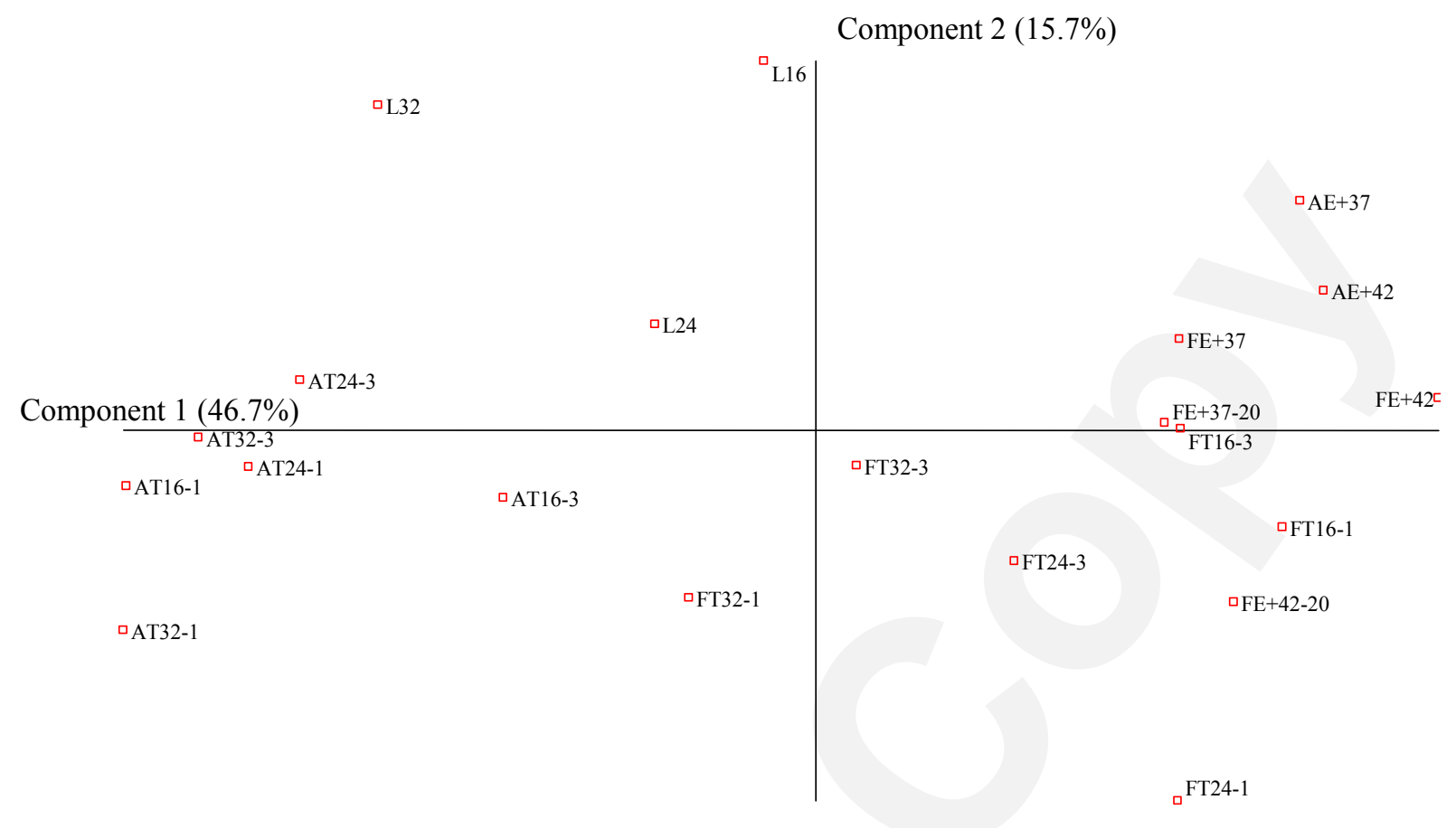


Figure 3.

565

566

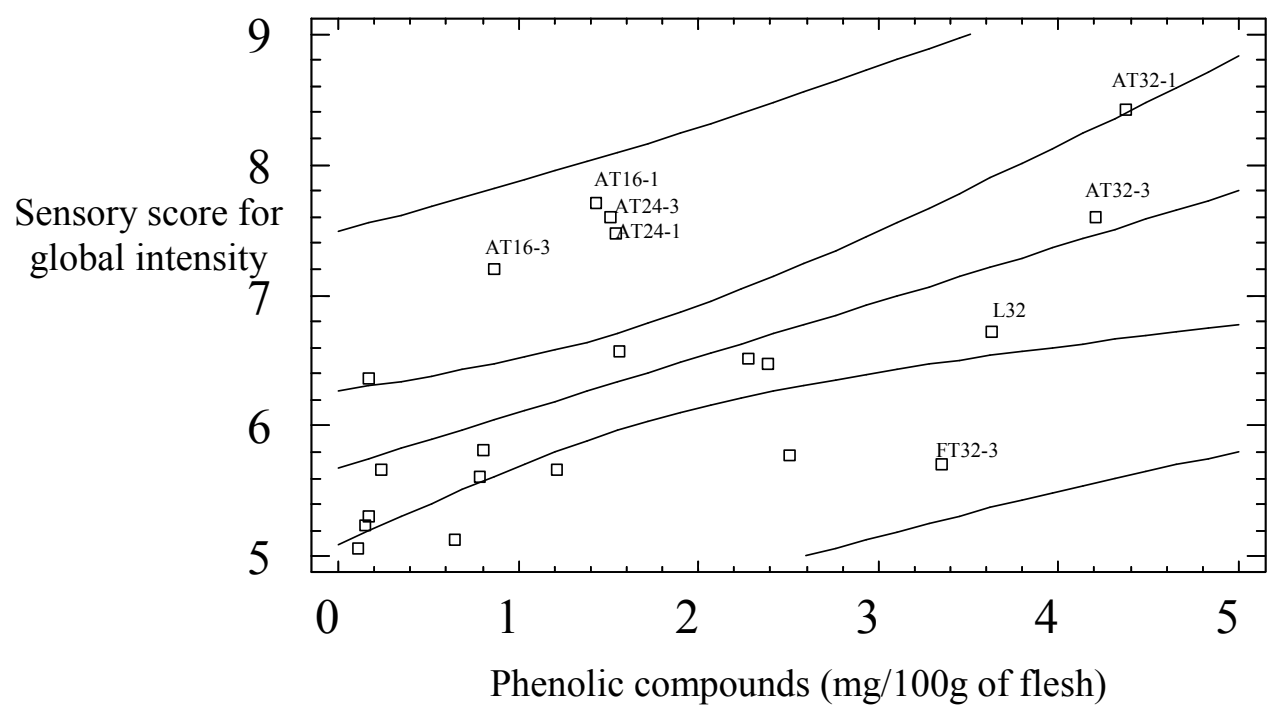

567

568

569

570 
570

571

572

573

Figure 4.

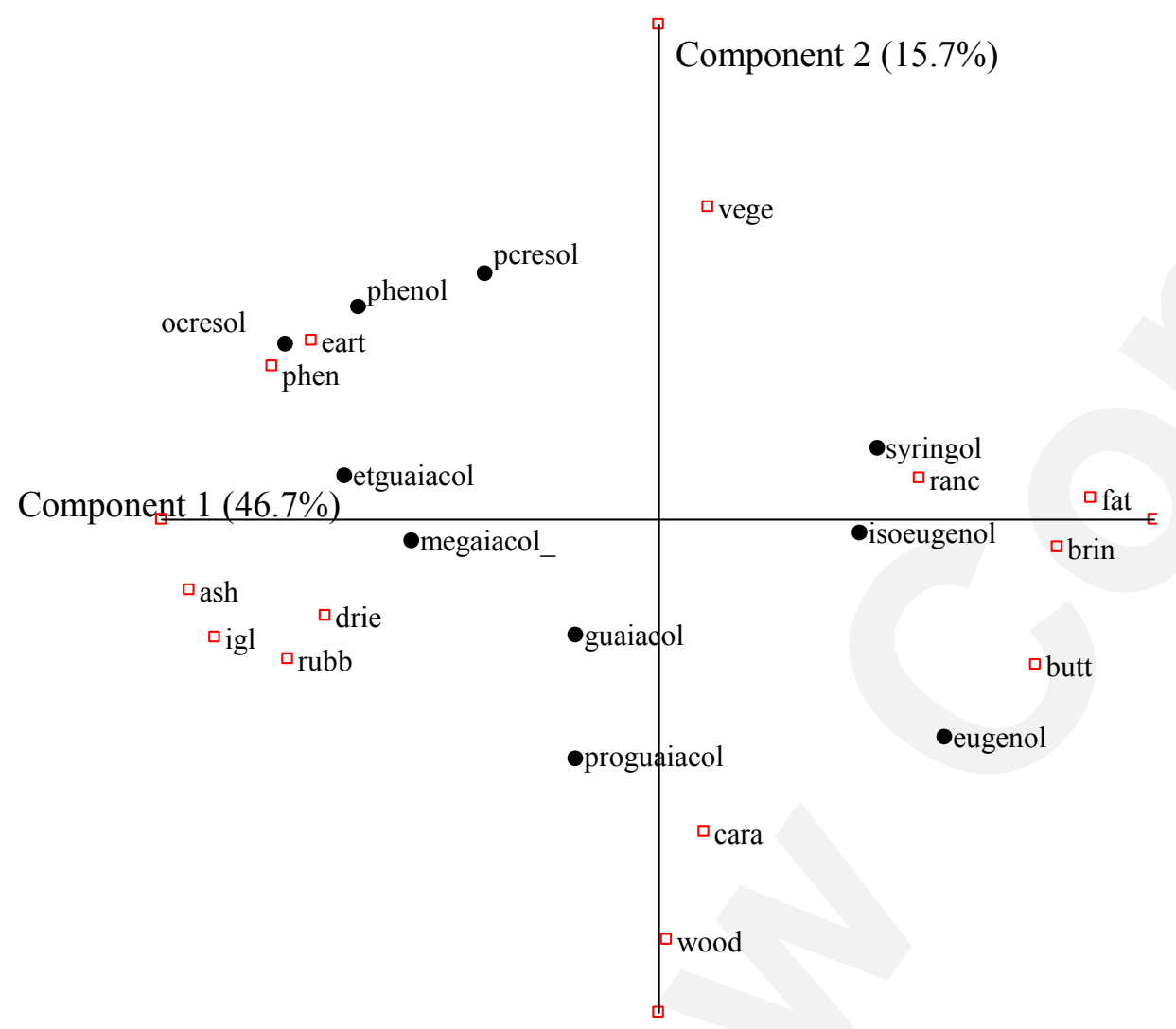

